\title{
O FENÔMENO DA ACUMULAÇÃO PRIMITIVA DO CAPITAL NO BRASIL COLÔNIA: APROXIMAÇÕES E DIFERENÇAS ENTRE AS ABORDAGENS DE CAIO PRADO JUNIOR E FERNANDO A. NOVAIS
}

\author{
EL FENÓMENO DE LA ACUMULACIÓN PRIMITIVA DE CAPITAL EN EL BRASIL \\ COLONIA: SIMILITUDES Y DIFERENCIAS ENTRE LOS ENFOQUES DE CAIO \\ PRADO JÚNIOR Y FERNANDO A. NOVAIS
}

\begin{abstract}
THE PHENOMENON OF THE PRIMITIVE ACCUMULATION OF CAPITAL IN COLONY BRAZIL: APPROXIMATIONS AND DIFFERENCES BETWEEN THE APPROACHES BY CAIO PRADO JÚNIOR AND FERNANDO A. NOVAIS
\end{abstract}

RESUMO: Em Formação do Brasil Contemporâneo, Caio Prado Júnior (1907-1990) indica que a história colonial brasileira porta determinada linearidade ou sucessão de eventos que se sobrepõem aos demais e revelam o sentido da colonização. Esse sentido está relacionado ao estabelecimento de ampla empresa mercantil nas colônias americanas com a finalidade de abastecer a economia europeia dos gêneros agrícolas existentes no Novo Mundo, antes de acesso extremamente limitado aos europeus. Posteriormente, essa contribuição de Caio Prado Júnior viria a ser complementada por Fernando A. Novais no livro Portugal e Brasil na Crise do Antigo Sistema Colonial (1777-1808), em que o historiador registra que a colonização não se restringia a tal grande empreendimento comercial exportador, mas constitui também iniciativa que revela uma das facetas fundamentais do desenvolvimento do capitalismo no século XVIII-XIX: o fenômeno da acumulação primitiva do capital.

PALAVRAS-CHAVE: Caio Prado Júnior. Fernando Novais. Economia colonial. Acumulação primitiva do capital.

RESUMEN: En 'Formación del Brasil Contemporáneo', Caio Prado Júnior (1907-1990) indica que la historia colonial brasileña lleva una cierta linealidad o sucesión de eventos que se superponen con los demás y revelan el sentido de la colonización. Ese sentido está relacionado con el establecimiento de una gran empresa comercial en las colonias americanas con el fin de abastecer la economia europea de los géneros agrícolas existentes en el Nuevo Mundo, que anteriormente tenían acceso extremadamente limitado a los europeos. Luego, esta contribución de Caio Prado Júnior sería complementada por Fernando A. Novais en el libro 'Portugal y Brasil em la Crisis del Antiguo Sistema Colonial (1777-1808)' (1978), en el que el historiador registra que la colonización no estaba restringida a esta gran empresa comercial exportadora, pero también constituye una iniciativa que revela una de las facetas fundamentales del desarollo del capitalismo en el siglo XVIII-XIX: el fenómeno de la acumulación primitiva del capital.

${ }^{1}$ Universidade Estadual Paulista (UNESP), Araraquara - SP - Brasil. Graduação em Ciências Sociais. ORCID: https://orcid.org/0000-0001-6079-5747. E-mail: vitornunes182.41@gmail.com 
PALABRAS CLAVE: Caio Prado Júnior. Fernando Novais. Economia colonial. Acumulación primitiva del capital.

ABSTRACT: In 'Formação do Brasil Contemporâneo', Caio Prado Júnior indicates that the brazilian colonial history carries a certain linearity or succession of events that overlap with the others and revel the sense of the colonization. This sense is related to the establishment of a large commercial enterprise in the american colonies with the purpose of supplying the european economy with the agricultural products found in the New World, which were of extremely limited access to the europeans before. Posteriorly, this contribution by Caio Prado Junior would be complemented by Fernando A. Novais in the book Portugal e Brasil na Crise do Antigo Sistema Colonial (1777-1808) (1978), in which the historian records that the colonization is not restricted to this large exporting commercial enterprise, but it also constitutes an initiative that reveals one of the fundamental facets of the development of capitalism in the XVIII-XIX century: the phenomenon of the primitive accumulation of capital.

KEYWORDS: Caio Prado Júnior. Fernando Novais. Colonial economy. Primitive accumulation of capital.

\section{Introdução}

Caio Prado Júnior (1907-1990) e Fernando Antônio Novais (1933-presente) desenvolveram contribuição complementar sobre a historiografia brasileira referente à economia colonial. Em Formação do Brasil Contemporâneo, livro publicado em 1942, Caio Prado Júnior expressa por meio da teoria do Sentido da Colonização a ideia de que o desenvolvimento do processo histórico no Brasil contém um sentido, uma "linha mestra" de eventos históricos que, uma vez encontrada, torna os demais acontecimentos tangenciais a ela e representa o caminho para o qual o desenvolvimento histórico, econômico e social do Brasil converge. Esse sentido está relacionado ao estabelecimento de grande produção agrária voltada ao abastecimento da economia europeia de produtos oriundos dos trópicos.

Essa contribuição decisiva é complementada posteriormente por Fernando Antônio Novais. O autor retoma a contribuição teórica feita por Caio Prado em sua tese de doutorado defendida em 1973, intitulada Portugal e Brasil na Crise do Antigo Sistema Colonial (17771808). Segundo Novais, Caio Prado Júnior estabeleceu importantes reflexões teóricas referentes ao processo histórico da colonização lusitana na América, porém este não se encerrava unicamente no pressuposto de que a colonização era somente uma empresa mercantil feita para suprir as necessidades da economia europeia. A colonização seria parte de um conjunto mais amplo, localizado no fenômeno da "acumulação primitiva de capital", conceito 
desenvolvido por Karl Marx ao se referir à forma como se deu a transição do feudalismo europeu para o capitalismo moderno.

Dessa forma, a pesquisa tem como objetivo geral investigar as relações estabelecidas entre a economia colonial brasileira e o chamado fenômeno da "acumulação primitiva do capital" utilizando as análises desenvolvidas por Caio Prado Júnior e Fernando Antônio Novais, com auxílio de outros pesquisadores que tiveram a economia colonial e o fenômeno da “acumulação primitiva do capital" como objeto de estudo.

\section{As origens da "acumulação primitiva do capital" na Europa}

A “acumulação primitiva do capital” é um fenômeno socioeconômico que remonta à Europa dos séculos XV-XVIII, contexto marcado pelas revoluções burguesas que modelaram todos os eventos políticos, econômicos e sociais da época. Aquelas revoluções, pode-se dizer, ocasionaram o sentido da colonização constante no conceito metodológico elaborado por Caio Prado Júnior. Aquele sentido pode ser encontrado nas revoluções burguesas, e um fenômeno peculiar a ele é a acumulação primitiva do capital.

De início, pode-se constatar que a polarização, em que se tem, de um lado, os detentores dos meios de produção, e do outro, os trabalhadores 'livres como os pássaros' (porém, nem escravos, nem camponeses), que vendem sua força de trabalho, é a condição básica para a existência do capitalismo. Assim, a "acumulação primitiva do capital" exprime a separação entre produtor e meios de produção, e possui o nome de 'primitiva' porque está relacionada com a anedota pré-histórica que Marx esboça fazendo analogia com o "pecado original" da Teologia: no caso, a situação do "pecado original” remonta à existência inicial de uma elite que acumulou riquezas em detrimento da distribuição igualitária dos bens materiais entre os indivíduos e grupos (SINGER, 1996).

O início do sistema capitalista é decorrente do fim do sistema feudal, levando o produtor a sofrer um duplo movimento histórico em que ele se desvencilha da servidão ao senhor feudal e das corporações e torna-se um trabalhador assalariado, libertando-se da coação de terceiros. Porém, ele também é forçado a "vender a si mesmo": separado dos meios de produção, os indivíduos ficam obrigados a vender a sua própria força de trabalho. O prevalecimento do capitalismo, portanto, resulta de uma luta vitoriosa contra os senhores feudais e a sua "exploração revoltante" que impunha entraves à livre "exploração do homem pelo homem" (SINGER, 1996).

Essa forma desigual de distribuição da riqueza social constitui o que há de mais 
marcante na história da "acumulação primitiva do capital", ou seja, a expropriação súbita e violenta de grandes massas de trabalhadores - fundamentalmente dos camponeses - dos seus meios de subsistência, sendo transformados em trabalhadores assalariados, ou 'proletários'. Porém, essa transformação se processou sob algumas particularidades de acordo com cada lugar em que ela ocorreu.

\section{Expropriações violentas na Inglaterra e Escócia durante os séculos XIV-XVIII}

Já no século XIV, a servidão começava a declinar na Inglaterra: existiam vários camponeses que exerciam trabalho autônomo e usavam o tempo livre para exercer a função social que viria a ser a dos proletários. No século XV esse quadro se consolidou, e o terreno inglês ficou todo dividido em vários senhorios "salpicados" de explorações camponesas. Aliás, nessa época, o poder do senhor feudal não era medido por sua renda, mas sim pela quantidade de camponeses economicamente autônomos que ele tinha trabalhando nas suas terras. Entretanto, não é esse ainda o início, ou, a base do modo de produção capitalista.

O fim do sistema feudal também se deu, afinal, pela violenta expropriação das terras dos camponeses. Os senhores feudais expulsaram os camponeses de suas terras, transformandoos em proletários, impulsionados pelo aumento da manufatura e da demanda de lã que se tornou o principal produto de cultivo das lavouras. Motivados pelo lucro crescente proporcionado pela industrial têxtil, os antigos senhores feudais utilizaram as terras das quais expulsaram os camponeses para criar ovelhas, criando grande massa de trabalhadores assalariados. Nesse processo, todas as antigas habitações dos camponeses foram destruídas.

Assim, em linhas gerais, é que se tem o surgimento da 'acumulação primitiva do capital', sobre a qual Singer (1996) faz uma breve reconstrução histórica cuja síntese, no que diz respeito à proletarização do camponês à época e da nova situação dele, é a seguinte: antes, pois, ele criava galinhas, porcos, ovelhas etc. em seu pedaço de terra, para a subsistência dele próprio e da família; agora, que ele foi expropriado de sua lavoura, ele se vê obrigado a ir para as cidades trabalhar como jornaleiro e/ou trabalhador de aluguel, para comprar no mercado as coisas de que precisa para viver, processo esse que favoreceu o crescimento das cidades e no qual Marx reconhece forte contradição, pois, ao mesmo tempo em que o pequeno proprietário, ou, arrendatário, é "promovido" a essa condição, torna-se mais difícil sustentar-se vivendo nela.

Por fim, Singer (1996) evoca a descrição feita por Marx da constituição do "último grande processo de expropriação dos lavradores da base fundiária": o "Clearing of Estates" (ou 
"clareamento, limpeza de propriedades"). Para explicar tal processo, Marx usa o exemplo da Escócia, onde o mencionado processo teve caráter peculiarmente grande e sistemático.

$\mathrm{Na}$ “Alta Escócia”, os celtas se organizavam em clãs, e cada um desses clãs era dono do respectivo solo que ocupava. O chefe do clã era apenas o proprietário titular do solo, assim como a rainha da Inglaterra é a proprietária titular do solo inglês. Quando o governo inglês conseguiu reprimir as guerras promovidas pelos clãs e as incursões deles nas planícies da "Baixa Escócia", os proprietários titulares dos clãs tomaram o solo como sua propriedade privada, e, como encontraram resistência por parte dos outros membros do clã, enxotaram-nos violentamente.

Após o último levante do pretendente - que refletiu a revolta dos povos da Escócia e da Inglaterra contra a exploração dos camponeses pelos senhores da terra e pela expropriação dos pequenos lavradores - ter sido derrotado, se sucedeu o fim do sistema de clãs e um grande aumento na expulsão dos camponeses de suas terras. Tal situação se intensificou posteriormente por conta de medidas tais como a ida forçada dos gaélicos expulsos da própria terra para Glasgow e outras cidades fabris e as 'clareações' feitas pela duquesa de Sutherland, que consistiram, basicamente, na transformação de todo o condado em pastagens de ovelhas, sendo expulsas e exterminadas milhares de famílias que viviam nessas terras. Inúmeras pessoas morreram, e às que sobreviveram foram destinadas pequenas porções de terra na orla marítima, que logo foram arrendadas pelos "grandes homens" dos clãs aos comerciantes de peixes de Londres.

Esse sofrimento imposto às Terras Altas segue como uma "necessidade agrícola", tal qual a devastação das florestas na América e na Austrália. Enfim, tudo isso conduziu ao seguinte cenário:

[...] a transformação usurpadora e executada com terrorismo inescrupuloso da propriedade feudal e clânica em propriedade privada moderna foram tantos outros métodos "idílicos" da acumulação primitiva. Eles conquistaram o campo para a agricultura capitalista, incorporaram a base fundiária para o capital e criaram para a indústria urbana a oferta necessária de um proletariado "livre como os pássaros" (SINGER, 1996, p. 355).

\section{Caio Prado Júnior e Fernando Antonio Novais: breves comentários}

A revisão bibliográfica do material escolhido para a pesquisa levou a algumas considerações preliminares sobre a história do Brasil Colônia e a sua relação com o fenômeno mais amplo da "acumulação primitiva do capital”. Uma delas é a já mencionada proximidade crítica com que Fernando Antônio Novais coloca a sua contribuição sobre a história colonial 
relacionada à de Caio Prado Júnior, criticando o trabalho deste por ter ficado "a meio caminho" na análise do período (MENDES, 2013).

Porém, Fernando Novais não deixa de considerar que o seu próprio trabalho descende em linhagem direta da teoria do sentido da colonização elaborada por Caio Prado Júnior (2011). Dessa forma, a teoria do sentido da colonização, apesar de ser fundamental na compreensão da história colonial, revela somente uma das faces da colonização, a comercial - e Fernando Antônio Novais criticou essa compreensão à medida em que foi além dela, tendo-a também como capitalista. O autor estabelece a relação de sua contribuição com a de Caio Prado Júnior da seguinte forma:

O principal procedimento de Novais para estabelecer sua relação com Caio Prado é o de considerá-lo como um historiador da colonização, sem relacionar a isso sua 'interpretação' ou 'teoria' da história do Brasil. Assim, Novais pôde apresentar-se como um historiador que aprofundou a maneira como Caio Prado entendeu a colonização. A partir de então, passou a assinalar que a colonização da época moderna constituiu um instrumento ou alavanca para promover a acumulação primitiva de capital nas metrópoles, último passo da transição do feudalismo para o capitalismo [...] (MENDES, 2013, p. 192).

Ainda, sobre essa teoria mesma e o que ela estabelece, pode-se dizer que há um marco temporal específico, datado do início do século XIX, e isso é uma escolha metodologicamente pensada e feita por Caio Prado Júnior, uma vez que esse período forneceu material historiográfico referente a dois séculos de atividade colonial, portanto, suficiente para que o autor desenvolvesse não somente a teoria do sentido da colonização, mas também outras, como a ideia de que o Brasil do século XX - sendo, afinal, o período em que vige o "Brasil Contemporâneo" cuja formação histórica e econômica é seu objeto de estudo no livro permanece, até o momento da publicação deste, sem completar a transição de uma economia colonial, ou seja, voltada para interesses alheios ao povo que vive na colônia, para uma economia nacional voltada aos interesses do povo e do Estado-nação:

[...] Essa opção, segundo ele [Caio Prado], é estratégica por um duplo motivo. De um lado, esse momento constitui uma espécie de balanço dos três séculos de atividade colonizadora. De outro, permite captar os primeiros passos do processo de transformação do organismo resultante da colonização. Essa transformação atravessara os oitocentos e ainda se 'arrastava' - segundo termo empregado pelo próprio autor - na época dele sem chegar a seu termo. Como afirmou, o Brasil contemporâneo se caracterizava pelo passado colonial, que se encerrava com o século XVIII, e pelas transformações que haviam ocorrido nos próximos séculos. [...] Desse modo, fica evidente que Caio Prado valoriza o estudo da economia colonial a partir do início do século XIX por dois motivos: primeiro, porque apresenta as características dessa economia; segundo, porque expressa os primórdios da sua transformação. Como a cabeça 
de Jano, permitiria olhar para trás e para a frente, para o passado e para o futuro (MENDES, 2013, p. 193).

Essa escolha metodológica, que enfoca a análise no início do século XIX, ao invés de, por exemplo, refletir mais detalhadamente sobre toda a atividade colonial desde a descoberta do território, evidentemente, não é casual. Não é, pois, o propósito de Caio Prado Júnior escrever "uma espécie de história da colonização do Brasil" (MENDES, 2013), mas captar os aspectos da economia e da sociedade à medida em que demonstra que eles remontam ao sentido da colonização, e, para isso, o início do século XIX, contendo três séculos de atividade colonial e sendo a "síntese" deles, não só fornece material historiográfico satisfatoriamente vasto, como também marca o momento em que se prepara "[...]nosso presente dos dias que correm", momento esse de transformações que, no entanto, “[...] se arrasta até hoje, e ainda não chegou a seu termo" (PRADO JÚNIOR., 2011, p. 6).

\section{Caio Prado Júnior e o 'Sentido da Colonização'}

No primeiro capítulo de Formação do Brasil Contemporâneo, Caio Prado Júnior analisa a colonização da América a partir do expediente metodológico denominado "teoria do sentido da colonização”. Essa metodologia constata que a evolução histórica de todo povo traz consigo um sentido, uma linha mestra de acontecimentos que permite ao pesquisador depreender do período em questão a particularidade central a ser investigada, eliminando as ocorrências tangenciais a essa linha principal de eventos históricos.

Esse conjunto principal de acontecimentos é encontrado na observação geral e ampla da sucessão histórica do desenvolvimento de um povo, o que torna clara e observável a evolução dele a partir do momento em que os pormenores que podem interferir na análise são colocados em segundo plano; nesse caso, a ocorrência principal se revela com maior clareza. Segundo Caio Prado Júnior, esse deve ser o método de interpretação da realidade brasileira: voltar a atenção para determinado período avançado de sua história sem deixar de considerar o seu passado. Afinal, é no passado que se encontra a continuidade que é a síntese do momento escolhido para a análise, o seu sentido. Sobre a importância desses eventos passados da história brasileira, Caio Prado Júnior faz as seguintes ponderações:

Isto nos leva, infelizmente, para um passado relativamente longínquo e que não interessa diretamente ao nosso assunto. Não podemos contudo dispensálo e precisamos reconstituir o conjunto da nossa formação colocando-a no amplo quadro, com seus antecedentes, destes três séculos de atividade colonizadora que caracterizam a história dos países europeus a partir do século 
$\mathrm{XV}$; atividade que integrou um novo continente na sua órbita [...] Processo [este] que acabaria por integrar o Universo todo em uma nova ordem, que é a do mundo moderno, em que a Europa, ou antes, a sua civilização, se estenderia dominadora por toda parte. Todos estes acontecimentos são correlatos, e a ocupação e povoamento do território que constituiria o Brasil não é senão um episódio, um pequeno detalhe daquele quadro imenso (PRADO JÚNIOR, 2011, p. 20).

Em seguida, o autor critica os "hábitos viciados de pensamento" que constituem algumas abordagens dessas passagens da História, colocando que é comum se ocupar com o fato da colonização em si sem considerar as motivações iniciais que moldariam o movimento histórico da empresa colonizadora, o que envolve refletir sobre a influência das particulares inclinações prévias de Portugal para realizá-la.

Feita essa ressalva, e, pode-se dizer, em razão dela, Caio Prado Júnior passa a analisar as expansões marítimas com o intuito de observar como elas alteraram a dinâmica do poder comercial na Europa, uma vez que a revolução na arte da navegação que a antecede transfere a primazia das rotas comerciais do centro europeu para o litoral, passando o domínio da atividade para os países que o compõem, tais como a Holanda, a Inglaterra e a Península Ibérica.

Esses novos líderes comerciais, em especial os portugueses, ganham então a prerrogativa de empreender o projeto das expansões ultramarinas que já vinha há décadas sendo preparado. O papel histórico dos portugueses acaba sendo pioneiro devido à sua localização geográfica que lhes ofereceu condições de tentar ir mais longe que os demais ao desembarcar no continente africano e contorná-lo para chegar às índias, onde encontrariam as especiarias. No encalço deles vieram os espanhóis, ingleses e holandeses.

Com exceção de alguns países, a Europa estava toda se aproveitando da nova ordem comercial vigente representada pelas Grandes Navegações. É importante ressaltar que o proveito tirado delas foi, a priori, estritamente comercial. A intenção de povoar os novos continentes se deu a partir do momento em que as empresas comerciais se tornaram mais complexas e passaram a demandar o estabelecimento territorial dos colonizadores na América - vale considerar, afinal, que no início dos Descobrimentos a Europa ainda tinha um contingente populacional comprometido por uma peste que devastou o continente nos dois séculos anteriores, e teria sérias dificuldades diante de um eventual deslocamento em massa para o Novo Mundo.

O povoamento do continente americano, em especial na parte de clima temperado, foi marcado principalmente pela fuga do conturbado contexto político-religioso europeu, empreendida pelos colonos em busca de abrigo em terras de características mais semelhantes 
ao continente em que eles viviam e agora se encontrava ameaçado por aqueles conflitos político-religiosos.

Soma-se a isso a transformação econômica vivida pela Inglaterra em meados do século XVI, em que campos de cultivo se transformam em pastagens de criação de carneiros cuja lã serviria para abastecer a nova indústria têxtil inglesa, processo que leva a várias correntes migratórias destinadas à América, majoritariamente para as áreas temperadas. Igualmente, os migrantes que iam para a região subtropical da América do Norte geralmente o faziam sem que lhes fosse dada a opção de ir para outras regiões, e logo procuravam sempre que possível as regiões temperadas.

Sobre esse tipo peculiar de colonização - o único do qual os portugueses não serão pioneiros - Caio Prado Júnior descreve da seguinte maneira os objetivos dos colonizadores que a empreenderam:

[...] O que os colonos desta categoria têm em vista é construir um novo mundo, uma sociedade que lhes ofereça garantias que no continente de origem já não lhes são mais dadas. Seja por motivos religiosos ou meramente econômico (estes impulsos aliás se entrelaçam e sobrepõem), a sua subsistência se torna lá impossível e muito difícil (PRADO JÚNIOR, 2011, p. 27).

Nas zonas tropicais e subtropicais, a colonização toma outro rumo. Afinal, as características físicas da região impunham dificuldades à adaptação dos colonos europeus, dada a diferença delas para com as encontradas no continente de onde vieram. Se até mesmo na América do Norte, em que houve uma seleção de um determinado tipo de colonizador pioneiro, o yankee, capaz de superar as dificuldades que o lugar propunha a quem viesse tentar povoá-lo, é de se imaginar que isso ocorreria ainda mais na América tropical, pondera Prado Júnior (2011). Por outro lado, a colonização aí se revelava muito promissora para objetivos de exploração, pois surgia a possibilidade de encontrar em abundância gêneros comerciais até então inexistentes, ou muito raros, na Europa.

Bastava, então, o esforço humano para obter esses novos recursos. Porém, o interesse do europeu neles não vinha acompanhado da intenção de explorá-los pelas próprias mãos. Por isso, eles visavam somente ser empresários de um negócio altamente rentável, e a contragosto como trabalhadores, pois sua ideia era que outros trabalhassem para eles. Isso dividiu, em grande medida, os que se dirigiram para a zona temperada do Novo Mundo e os que foram para os trópicos. Para estes, só iam os que dispunham de um contingente de mão de obra suficiente para que se realizasse as suas ambições comerciais sem muito esforço próprio. Em 
contrapartida, os que podiam ser dirigentes eram favorecidos pela produção agrária feita no continente quase sempre em larga escala e dependente de muitos trabalhadores.

Assim, no caso das colônias inglesas, colonos se dispuseram a migrar para a América para trabalhar nas grandes lavouras em troca do transporte que não podiam pagar. Eles constituíram a mão de obra das colônias do Novo Mundo até a sua substituição definitiva pela mão de obra escravizada a partir do século XVII. Quanto às colônias tropicais, inclusive o Brasil, isso não ocorreu devido ao contingente populacional lusitano ter sido desde o século XVI já bastante frágil, sendo uma das razões dessa fragilidade justamente as expedições. Além disso, os portugueses e espanhóis puderam se aproveitar da mão de obra indígena e, por fim, tem-se que os portugueses já dominavam a escravidão de negros, assim como os territórios que os forneciam, e foram pioneiros em adotá-la em suas colônias.

Dessa forma, a colonização nos trópicos foi organizada de maneira diferente daquela que ocorreu nas colônias de zona temperada. Enquanto nestas predominou o povoamento, o carro chefe daquelas se manteve sendo o motivo inicial das expedições marítimas, ou seja, uma grande empresa comercial "[...] mais completa que a antiga feitoria, mas sempre com o mesmo caráter que ela" (PRADO JÚNIOR, 2011, p. 31). Essa empresa comercial estava voltada à exploração dos recursos naturais de territórios jamais aproveitados anteriormente. Esse é o sentido da colonização tropical, e o Brasil não só é elemento resultante disso, mas tem nele fatores fundamentais de seu desenvolvimento econômico e social.

\section{Fernando Antônio Novais e a 'Acumulação Primitiva do Capital' na Colonização}

A partir da abordagem de Caio Prado Júnior, feita em Formação do Brasil Contemporâneo sobre a colonização do Novo Mundo, abre-se caminho para uma nova interpretação do caráter da economia colonial, que viria a ser elaborada por Fernando Antônio Novais em sua tese de doutorado defendida em 1973, intitulada Portugal e Brasil na Crise do Antigo Sistema Colonial (1777-1808). Esse trabalho é tributário da teoria de Caio Prado à medida em que ressignifica os pressupostos que ela estabelece.

O autor reconhece a importância da interpretação de Caio Prado Júnior sobre a história nacional, mas observa que ela permaneceu incompleta (MENDES, 2013). Segundo Fernando Antônio Novais, Caio Prado Júnior estabeleceu importantes reflexões referentes ao sentido da colonização, porém, a análise do processo histórico da colonização lusitana na América não se encerrava unicamente no pressuposto de que ela era somente empresa mercantil que supria as necessidades da economia europeia. 
No fundo, ao repensar o conceito do sentido da colonização, Fernando Antônio Novais assinala que Caio Prado Júnior não descreveu a colonização em todos os seus desdobramentos econômicos, políticos e sociais. A colonização seria apenas parte de um contexto amplo de desenvolvimento das forças produtivas pelo qual o capitalismo passava à época, o fenômeno da “acumulação primitiva de capital”, que marcava a transição do feudalismo europeu para o capitalismo moderno. A teoria do sentido da colonização revela somente a face da colonização comercial, e Fernando Antônio Novais vai além, pressupondo-a também capitalista ao analisar a crise do Antigo Sistema Colonial.

O Antigo Regime, afinal, começou a se dissolver a partir das revoluções do final do século XVIII e início do XIX, tendo início na Revolução Industrial na Inglaterra e consolidando-se na Revolução Francesa. O desenvolvimento desse duplo processo revolucionário igualmente se alastrou por todo o mundo. Essa sucessão de eventos arrebatou a sociedade ocidental como um todo ao inaugurar a contemporaneidade histórica e todas as instituições que dela são características, e o Antigo Sistema Colonial começou a ruir gradualmente ao ser influenciado pelo novo movimento revolucionário. É nesse cenário histórico de amplas proporções que o Brasil emergiu como nação soberana ao modificar profundamente as suas relações econômicas e políticas para com a antiga metrópole lusitana (NOVAIS, 1981).

Assim, a investigação empreendida por Fernando Antônio Novais é resultado da tentativa de pensar o Brasil em meio a esses dois contextos: o panorama geral e mais profundo da dissolução do Antigo Sistema Colonial que então ocorria mundialmente, e a conjuntura específica na qual se desdobrava a relação do Brasil para com Portugal nessa mesma época.

Para explicar como esse sistema colonial entrara em crise, Fernando Antônio Novais considerou as características que permitem distinguir o Antigo Sistema Colonial dos demais, uma vez que o ser humano povoou, ocupou e se apropriou das terras do planeta de diversas maneiras ao longo da história.

A forma de colonização que se formou na Época Moderna - ocorrida entre os Descobrimentos e a Revolução Industrial - estava relacionada ao sistema mercantilista de colonização. Essa constatação tem respaldo em dois fatores: 1) $\mathrm{O}$ aparato legal referente à colonização europeia da época, correspondente ao plano concreto das relações entre as metrópoles e colônias; 2) Os princípios formulados pela teoria mercantilista, que serviam em um plano mais abstrato como orientação para a elaboração e execução dessas leis.

Embora a influência desses esquemas abstratos de pensamento na realidade fosse limitada, Fernando Antônio Novais pondera que foi fundamental a existência de um "projeto 
básico" mercantilista a informar a atuação das colônias, principalmente no que diz respeito à importância que elas tinham para as metrópoles. O autor delineia "[...] as linhas mestras da doutrina, para situar nela o papel do colonialismo mercantilista" (NOVAIS, 1981, p. 61), descrevendo-o da seguinte forma:

\begin{abstract}
Neste contexto, vê-se bem o significado e a posição das colônias. Elas se devem constituir em retaguarda econômica da metrópole. Pois que a política mercantilista ia sendo praticada pelos vários estados modernos em desenfreada competição, necessário se fazia a reserva de certas áreas onde se pudessem por definição aplicar as normas mercantilistas; as colônias garantiriam a autossuficiência metropolitana, meta fundamental da política mercantilista, permitindo assim ao Estado colonizador vantajosamente competir com os demais concorrentes (NOVAIS, 1981, p. 61-62).
\end{abstract}

Assim, ter-se-ia metrópole e colônia como dois polos de um mesmo eixo, em que uma funciona como centro de decisões e a outra como componente subordinado dessas decisões ao prover a segurança da competitividade econômica para a metrópole. Esse é um esboço do funcionamento do Antigo Sistema Colonial sob ideário mercantilista. Porém, essa é uma caracterização preliminar e incompleta do sistema, sendo necessário recorrer a aspectos fundamentais do próprio todo em que o sistema capitalista da Era Moderna ocorre para se analisar as formas como o Antigo Sistema Colonial nele se situa.

Em verdade, Fernando Antônio Novais delineia os aspectos gerais da Era Moderna sob o recorte de um contexto específico: as expedições ultramarinas e a crise social que levou à formação dos Estados nacionais. Este evento contribuiu para que aquele fosse, em alguma medida, bem-sucedido e lucrativo.

O cenário comercial europeu ocidental se encontrava sacudido por uma crise social que foi, em última instância, respondida com a centralização do poder político em torno de lideranças monárquicas absolutistas que conferiram viabilidade ao improvável e arriscado investimento que era o sistema colonial. A prévia organização social europeia em torno dos centros comerciais medievais era incapaz de realizar a acumulação de capital necessária para isso.

Assim, a colonização pode ser considerada o desdobramento de uma grande empresa comercial que reorganiza um sistema econômico que incluía as colônias como novos centros produtores, e não mais somente espaços de circulação de mercadorias. A partir dessas considerações é que Fernando Antônio Novais se aproxima do conceito do sentido da colonização de Caio Prado Júnior, atestando-o como verdadeiro à medida em que a complementa partindo de suas considerações sobre o Antigo Regime. Afinal, o estabelecimento 
dos Estados nacionais - somado à dissolução paulatina do modo de produção feudal, ao desenvolvimento da produção nas colônias e ao surgimento de uma burguesia mercantil - não só faz recrudescer o objetivo inicial da colonização, ou seja, o abastecimento da economia europeia dos gêneros agrícolas do Novo Mundo, como promove a chamada acumulação primitiva do capital.

Em sua já mencionada tese de doutorado, Fernando Antônio Novais coloca que "o ponto de partida para a caracterização da economia colonial é o sentido mais profundo da colonização e o mecanismo da base das relações metrópole-colônia" (NOVAIS, 1981, p. 92). A economia colonial revela um profundo processo de desenvolvimento das forças produtivas: primeiro, o surgimento de uma produção local feita para o consumo dos povoadores; em segundo, o aumento dessa produção e a adoção do chamado sistema de plantation, que então passa a alimentar os quadros da economia europeia. Esse processo corresponde ao fenômeno da acumulação primitiva do capital desenvolvido no Brasil Colônia. Em todas as colônias, configura-se um mesmo processo de aceleração da acumulação do capital que Fernando Antônio Novais resume da seguinte forma:

No conjunto, portanto, é possível divisar o movimento geral que caracteriza a montagem da colonização moderna dentro dos mecanismos do sistema colonial: povoamento inicial, com produção para o consumo local; em seguida, entrosamento nas linhas do comércio europeu, e, pois, nos mecanismos da economia reprodutiva europeia. Ao passarem a produzir para o mercado externo, articulavam-se no sistema pois o regime desse comércio e como já vimos o nervo do sistema. Destarte, ajusta-se a colonização ao sentido do sistema colonial do capitalismo mercantil: através da exploração das áreas ultramarinas promovia-se a originária acumulação capitalista na economia europeia" (NOVAIS, 1981, p. 96).

Sendo a acumulação capitalista o corolário da expansão ultramarina e da colonização, impunha-se intensiva aceleração no ritmo das exportações, cujo fim era suprir as necessidades do mercado europeu. Nessas condições, a acumulação capitalista carecia cada vez mais de formas de trabalho compulsório, principalmente o escravismo. Isso era, evidentemente, um contrassenso à mentalidade da época, considerando que a escravidão já era dada como anacrônica e imoral no Velho Mundo, e uma das principais características da formação do capitalismo era a alienação do trabalhador dos meios de produção, tornando-o livre de quaisquer vínculos servis, ou seja, sem nada que não seja sua própria força de trabalho para vender e fazer o próprio sustento.

Sendo assim, o que explica o uso em larga escala do trabalho compulsório nas colônias, se elas foram instrumento da acumulação primitiva do capital, etapa fundamental de 
consolidação do capitalismo? Sobre esse questionamento, Fernando Antônio Novais pondera que o uso de formas de trabalho forçado nas colônias não foi em momento algum opcional, pois, se em vez disso se utilizasse trabalho assalariado, os trabalhadores teriam, ao contrário do que ocorria na Europa, condições para se tornarem produtores e constituírem uma economia de subsistência independente das necessidades econômicas metropolitanas, contrariando o sentido da colonização, que era o corolário do Antigo Sistema Colonial:

[...] Efetivamente, nas condições históricas em que se processa a colonização da América, a implantação de formas compulsórias de trabalho decorria fundamentalmente da necessária adequação da empresa colonizadora aos mecanismos do Antigo Sistema Colonial, tendente a promover a primitiva acumulação capitalista na economia europeia; do contrário, dada a abundância de um fator de produção (a terra), o resultado seria a constituição no Ultramar de núcleos europeus de povoamento, desenvolvendo uma economia de subsistência voltada para o seu próprio consumo, sem vinculação efetiva com os centros dinâmicos metropolitanos. Isto, entretanto, ficava fora dos impulsos expansionistas do capitalismo mercantil europeu, não respondia às suas necessidades (NOVAIS, 1981, p. 102).

Ou seja, a manutenção de variadas formas de trabalho compulsório durante a colonização da América foi, em última instância, uma manifestação do fenômeno da “acumulação primitiva do capital” adaptado ao contexto social e geográfico daqui, uma vez que o surgimento dele na Europa se deu sob condições que, embora muito diferentes das que tiveram lugar na América, eram de vital importância para a empresa colonizadora, e, como tal, não poderiam ter sua continuidade comprometida por um eventual desvio de seus objetivos originais.

\section{Considerações finais}

As obras de Caio Prado Júnior e Fernando Antônio Novais fundam importantes referenciais teóricos para a análise de vários aspectos da economia e da sociedade colonial. Ambos produziram interpretações do Brasil que influenciam o debate acadêmico atual referente à conjuntura econômica e social da colonização portuguesa na América. Esta pesquisa remonta, com efeito, à teoria do sentido da colonização elaborada por Caio Prado Júnior em Formação do Brasil Contemporâneo e a sua relação para com a interpretação que Fernando Novais desenvolve em Portugal e Brasil na Crise do Antigo Sistema Colonial (1777-1808). Em síntese, Fernando Novais afirma que a teoria de Caio Prado Júnior revela mais do que o seu autor enxergou em sua análise, guardando relação para com o desenvolvimento do modo de produção 
recém estabelecido na maior parte do mundo a partir das revoluções burguesas por meio da chamada acumulação primitiva do capital.

Essa interpretação conjunta e complementar (de modo que uma fica incompleta sem a outra) desenvolvida por Caio Prado Júnior e Fernando Antônio Novais é de suma importância para a historiografia brasileira, até mesmo por ser a raiz da noção que muito comumente se aprende a ter sobre a economia colonial na escola quando dos primeiros contatos com esse tema. A robustez teórica de que ela se reveste, em verdade, a credencia como informação indispensável na formação de jovens conscientes e aptos à cidadania (ainda que sua importância não seja unânime, ou, paradigmática, em âmbito acadêmico, de que se tem exemplo na abordagem da chamada 'Escola do Rio', enfocada na economia interna e de subsistência desenvolvida em partes do território brasileiro durante o período colonial em detrimento da ênfase dada pelos autores mais clássicos e conhecidos da historiografia brasileira - Caio Prado Júnior, Gilberto Freyre e Sérgio Buarque de Hollanda².

Por fim, vale ressaltar a atualidade das obras Formação do Brasil Contemporâneo e Portugal e Brasil na Crise do Antigo Sistema Colonial (1777-1808), considerando a conjuntura econômica já amplamente debatida referente ao processo de desindustrialização e ampliação do setor terciário da economia brasileira, em que se tem, basicamente, a atividade industrial brasileira recuando por sucessivas décadas, sob perspectivas tais como geração de empregos e participação no PIB, entre outras utilizadas na literatura econômica para mensurar a participação industrial brasileira na economia durante as últimas décadas ${ }^{3}$, ao passo que novas tecnologias estrangeiras invadem cada vez mais o dia-a-dia da sociedade, vide a chamada 'uberização' e crescente automação das relações de trabalho (ALMEIDA, 2018), ao mesmo tempo em que o Brasil se afasta do preparo necessário para absorver as mudanças que o mundo contemporâneo impõe a tudo e todos com revoluções industriais que sucederam à primeira - e disso decorrem variadas externalidades tais como insegurança jurídica para trabalhadores, aumento do desemprego, entre outras. A primeira Revolução Industrial se inclui, por sinal, entre os principais eventos históricos e econômicos que influenciaram as mudanças de que tratam Caio Prado Júnior (2011) e Fernando Antônio Novais (1981).

${ }^{2}$ Ver Silva (2014).

${ }^{3}$ Ver Oreiro e Feijó (2010). 


\section{REFERÊNCIAS}

ALMEIDA, C. A uberização do trabalho no século XXI. Época, São Paulo, 28 maio 2018. Disponível em: https:/epoca.globo.com/tecnologia/noticia/2018/05/uberizacao-do-trabalhono-seculo-xxi.html. Acesso em: 14 set. 2020.

JÚNIOR, C. P. Formação do Brasil Contemporâneo. São Paulo: Companhia das Letras, 2011.

MENDES, C. M. M. Um estudo sobre a relação entre Caio Prado Júnior e Fernando A. Novais. Acta Scientiarum, Human and Social Sciences, Maringá, v. 35, n. 2, p. 189-199, jul./dez. 2013.

NOVAIS, F. A. Portugal e Brasil na crise do antigo sistema colonial (1777-1808). 5. ed. São Paulo: HUCITEC, 1981.

OREIRO, J. L.; FEIJÓ, C. A. Desindustrialização: conceituação, causas, efeitos e o caso brasileiro. Revista de Economia Política, São Paulo, v. 30, n. 2, p. 219-232, abr./jun. 2010.

SILVA, C. C. da. Repensando o Brasil Colonial: uma análise comparativa entre as obras Formação do Brasil Contemporâneo e Homens de Grossa Aventura. In: ENCONTRO REGIONAL DE HISTÓRIA, 14., 2014, Campo Mourão. Anais [...]. Campo Mourão: Universidade Estadual do Paraná, 2014. p. 1951-1962.

SINGER, P. A assim chamada acumulação primitiva do capital. In: Os economistas. São Paulo. Nova Cultural, 1996.

\section{Como referenciar este artigo}

NUNES AMOROSO, V. O fenômeno da acumulação primitiva do capital no Brasil colônia: aproximações e diferenças entre as abordagens de Caio Prado Junior e Fernando A. Novais. Rev. Sem Aspas, Araraquara, v. 9, n. 1, p. 140-155, jan./jun., 2020. e-ISSN: 2358-4238. DOI: https://doi.org/10.29373/sas.v9i1.13336

Submetido em: 20/04/2020

Revisões requeridas: $30 / 06 / 2020$

Aprovado em: 01/07/2020

Publicado em: 30/09/2020 